\title{
Current Management of Urethral Stricture
}

\author{
Young Ju Lee, Soo Woong Kim \\ Department of Urology, Seoul National University Hospital, Seoul, Korea
}

The surgical treatment of urethral stricture diseases is continually evolving. Although various surgical techniques are available for the treatment of anterior urethral stricture, no one technique has been identified as the method of choice. This article provides a brief updated review of the surgical options for the management of different sites and different types of anterior urethral stricture. This review also covers present controversies in urethral reconstruction. Among the various procedures available for treating urethral stricture, one-stage buccal mucosal graft urethroplasty is currently widely used. The choice of technique for urethroplasty for an individual case largely depends on the expertise of the surgeon. Therefore, urologists working in this field should keep themselves updated on the numerous surgical techniques to deal with any condition of the urethra that might surface at the time of surgery.

\section{Keywords: Urethra; Urethral stricture; Urethroplasty}

This is an Open Access article distributed under the terms of the Creative Commons Attribution Non-Commercial License (http://creativecommons.org/licenses/by-nc/3.0) which permits unrestricted non-commercial use, distribution, and reproduction in any medium, provided the original work is properly cited.

\author{
Article History: \\ received 3 June, 2013 \\ accepted 26 June, 2013 \\ Corresponding Author: \\ Soo Woong Kim \\ Department of Urology, Seoul \\ National University Hospital, \\ 101 Daehak-ro, Jongno-gu, Seoul \\ 110-744, Korea \\ TEL: +82-2-2072-2426 \\ FAX: +82-2-742-4665 \\ E-mail: swkim@snu.ac.kr
}

\section{INTRODUCTION}

The male urethra can be divided into two parts: the posterior urethra, including the membranous and prostatic urethra, and the anterior urethra. The anterior urethra classically is divided into the bulbar and the penile urethra. Basically, the term urethral stricture refers to anterior urethral disease by consensus of the World Health Organization conference [1]. In contrast, posterior urethral "strictures" are not included in the common definition of urethral stricture. Distraction defects are processes of the membranous urethra associated with pelvic fracture. Other narrowings of the posterior urethra are termed urethral contractures or stenoses [1].

The bulbar urethra is enclosed by the bulbospongiosus muscle and the penile urethra runs from the distal margin of the bulbospongiosus to the fossa navicularis and external meatus. Surgical treatment of urethral stricture diseases is continually evolving. Although various means of reconstructing the urethra exist, the best technique has not yet been clearly defined [2]. The urologist must be up-to-date with the use of numerous surgical techniques to deal with any condition of the urethra that might surface at the time of surgery.

This review article aims to provide an update on the man- agement of anterior urethral strictures, with a focus on options for urethroplasty at different sites and for different types of stricture.

\section{MANAGEMENT OF BULBAR URETHRAL STRICTURE}

According to the results of a nationwide survey, direct vision internal urethrotomy (DVIU) is used for most urethral strictures in the United States [3] and the situation is similar in Korea. Many urologists erroneously believe that there is a "reconstructive ladder" and that urethroplasty is considered only after successive failed dilations or urethrotomies [3]. However, repeated DVIU can increase the length and density of spongiofibrosis, thus making definitive surgical intervention more difficult [4]. The most cost-effective strategy for the management of short, bulbar urethral strictures is to reserve urethroplasty for patients in whom a single DVIU fails [5]. Meanwhile, it might be more cost-effective to go straight to primary urethroplasty because most patients want a cure [6].

\section{End-to-end anastomosis}

In the bulbar urethra, the surgical technique should be selected mainly according to stricture length, but the stric- 

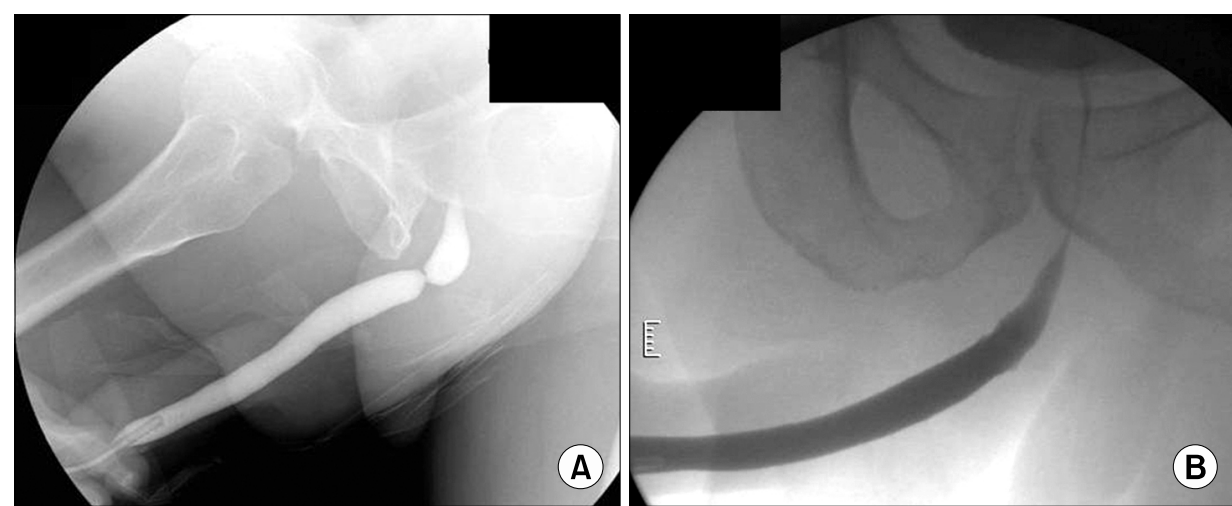

FiG. 1. Representative retrograde urethrography. (A) Preoperative retrograde urethrography in a patient with a short bulbar urethral stricture following straddle injury. (B) Normal retrograde urography 2 weeks after excision and end-to-end anastomosis. ture etiology and density of the spongiofibrosis tissue should be taken into account [7]. The gold standard for the treatment of a short stricture of the bulbar urethra is excision, spatulation of the two ends, and an end-to-end anastomosis, whether the lumen is completely occluded or not (Fig. 1) [2].

Short bulbar strictures are generally amenable to complete excision with primary anastomosis via a perineal incision, affording a high success rate of $95 \%$, as reported by Santucci et al. [8]. Eltahawy et al. [9] published their series of 260 patients with bulbar stricture who underwent end-to-end anastomosis with a mean follow-up of 50.2 months. The stricture length ranged 0.5 to $4.5 \mathrm{~cm}$ (mean, $1.9 \mathrm{~cm}$ ) and the authors reported a success rate of $98.8 \%$. Recently, Barbagli et al. [10] described a success rate of 90.8\% in 153 patients who underwent bulbar end-to-end anastomosis with a mean follow-up of 68 months.

The ideal stricture length for excision and end-to-end anastomosis has been a contentious issue. Guralnick and Webster [11] insisted that this operation should be limited to strictures of $1 \mathrm{~cm}$ or less, because excision of a 1-cm urethral segment with opposing 1-cm proximal and distal spatulations results in a 2 -cm urethral shortening. They emphasized that excision of a longer urethral segment risks penile shortening or chordee [11]. In general, the stricture length best manageable by excision and primary anastomosis is $2 \mathrm{~cm}$ or less [9,12].

However, strictures longer than $2 \mathrm{~cm}$ can be managed successfully in selected patients with end-to-end anastomosis [8-10]. Morey and Kizer [13] reported on a selected cohort of 22 patients with proximal bulbar urethral strictures longer than $2.5 \mathrm{~cm}$ treated with an extended anastomotic approach and suggested that urethral reconstructability is proportional to the length and elasticity of the distal urethral segment. They reported a $91 \%$ success rate, concluding that defects up to $5 \mathrm{~cm}$ can be successfully excised and primarily reconstructed in select young men with proximal bulbar strictures [13].

The impact of previous treatment on surgical outcomes is controversial. In the recent series reported by Santucci et al. [8] and Eltahawy et al. [9], 55\% and $69.2 \%$ of patients had a history of failed attempts of urethroplasty or DVIU, respectively, and despite this, surgical outcomes were equally excellent. By contrast, in the study by Barbagli et al. [10], the only group of patients who had a lower success rate $(78.6 \%)$ had undergone multiple treatments (dilation, DVIU, or urethroplasty), whereas the other groups (prior single or no treatment) showed similar success rates ranging from $92.1 \%$ to $100 \%$ without any statistical significance. It was also suggested that endoscopic or open urethral manipulation before anastomotic urethroplasty for posttraumatic urethral stricture has a significant impact on the outcome of urethral reconstruction [14].

\section{1) Nontransecting anastomosis}

Recently, Andrich and Mundy [15] developed a novel approach to the excision and end-to-end anastomotic repair of bulbar urethral strictures without transecting the urethra. Transecting the urethra allows complete removal of scarred tissue but may cause vascular and neuronal damage to the urethra, thus promoting urinary and sexual dysfunction [16]. By contrast, the nontransecting technique, in which the corpus spongiosum is not transected, allows intact maintenance of the blood supply $[15,16]$. Andrich and Mundy [15] used this technique in 22 patients (mean age, 34 years). After mobilization of the urethra, a dorsal stricturotomy was made sufficient to open into the normal caliber urethra on either side. The urethral stricture was excised with the surrounding spongiofibrosis in 18 of 22 patients, leaving the healthy ventral spongiosum intact. In 4 of the 22 patients the urethra was simply opened longitudinally and closed transversely at the site of the stricture. Of 16 patients who had been followed up for a minimum of 1 year, surgery was successful in all (100\%) [15]. The authors argued that the only indication for urethral transection nowadays is urethroplasty after urethral trauma when, in many instances, there is a more or less obliterated segment of the urethra [15].

\section{Substitution urethroplasty}

The gold standard for a long bulbar stricture $(\geq 2 \mathrm{~cm})$, where the urethral lumen is relatively well preserved and the spongiofibrosis around the lumen is limited, is a stricturotomy and dorsal patch substitution urethroplasty using a buccal mucosal graft (BMG), with success rates higher than $90 \%$ [17-19]. This is commonly called the Barbagli 

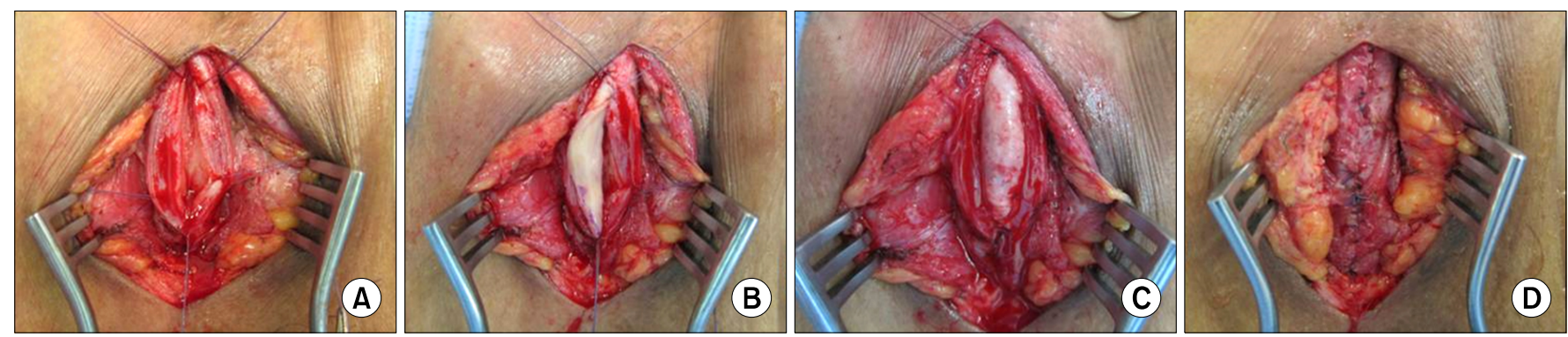

Fig. 2. Intraoperative picture of a substitution urethroplasty with ventral onlay buccal mucosal graft (BMG). (A) The corpus spongiosum is opened along ventral surface and the urethral lumen is fully exposed proximally and distally to the stricture. Then the length and width of the BMG required for the augmentation are measured. (B) BMG is trimmed to its appropriate size and the two ends of the graft are sutured to the proximal and distal end of the urethrotomy. Running suture is used to complete a watertight anastomosis between the right margin of the BMG and the right margin of the urethral mucosal plate. (C) The graft is rotated over the catheter and a running suture is completed on the opposite margin of the graft and the urethral mucosa. (D) The spongiosum is closed over the BMG using interrupted sutures.
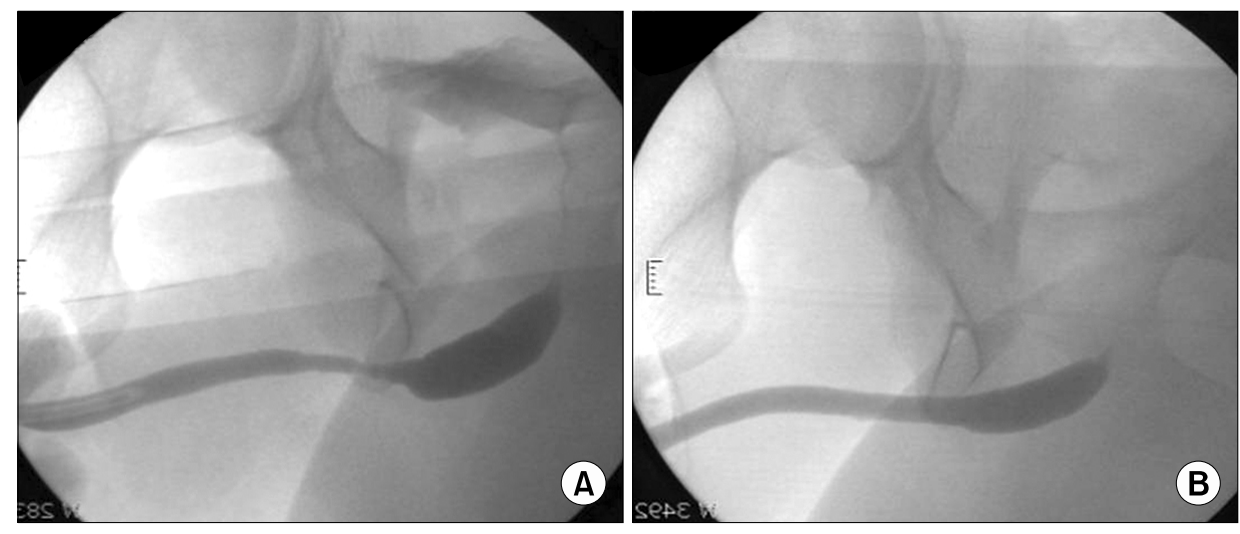

FiG. 3. Retrograde urethrographic appearance before (A) and after (B) surgery in the same patient (Fig. 2).

procedure. The lip is no longer popular because of the potential morbidity of harvesting from that site compared with the cheek [20]. In recent years, dorsal stricturotomy with patching and ventral stricturotomy with patching have become equally popular [21,22]. In one meta-analysis, BMG had the highest success rate $(88.1 \%)$ and the success rate was similar between the dorsal and ventral onlay techniques $(89.2 \%$ vs. $87.6 \%, p=0.472)$ [22]. The advantage of a ventral onlay graft is that it is an easier approach with less mobilization of the urethra but the stricturotomy is into the most vascular and thickest part of the urethra; thus, there is more bleeding and the graft appears to be less secure [20]. The surgical techniques of ventral onlay BMG were illustrated well by Barbagli et al. [23]. Figs. 2 and 3 show a representative case and results. The suggested benefits of a dorsal onlay graft consist of less bleeding from the thinnest and least vascular aspect of the urethra and quilting of the graft onto the tunica albuginea, which is much more secure; however, the procedure is technically more demanding [24]. Recently, Kulkarni et al. [25] performed a new one-sided anterior dorsal BMG urethroplasty with preservation of the lateral vascular supply to the urethra, the central tendon of the perineum, the bulbospongiosus muscle, and its perineal innervation.

\section{Augmented anastomotic urethroplasty}

Guralnick and Webster [11] described a technique that combines the principles of excision and anastomosis with those of onlay grafting for long bulbar urethral strictures that contain a 1 - to $2-\mathrm{cm}$ area that is particularly narrow and dense. In this technique, the segmental excision of the worst section of the stricture (but only up to $2 \mathrm{~cm}$ ) is followed by anastomosis of the dorsal or ventral urethral wall. Guralnick and Webster [11] used this technique in 29 patients with bulbar urethral strictures with a success rate of $93 \%$ at a mean follow-up of 28 months. They used ventral onlay in 9 and dorsal onlay in 20 patients. Abouassaly and Angermeier [26] reported their experience of augmented anastomotic urethroplasty in 69 patients with a success rate of $90 \%$ at a mean follow-up of 34 months. In 58 patients $(84 \%)$ the graft was placed ventrally, whereas in $11(16 \%)$ it was placed in the dorsal position. Originally, the dorsal onlay introduced by Barbagli et al. [17] was favored to avoid pseudodiverticulum formation and sacculation of the graft and to offer a good bed for the graft take [11]. El-Kassaby et al. [27] reported the largest series using augmented anastomotic urethroplasty with ventral BMG onlay. They reported a success rate of $93.7 \%$ in 233 patients with a mean follow-up of 36 months. The authors described that sacculation or pseudodiverticulum formation is more prone to 

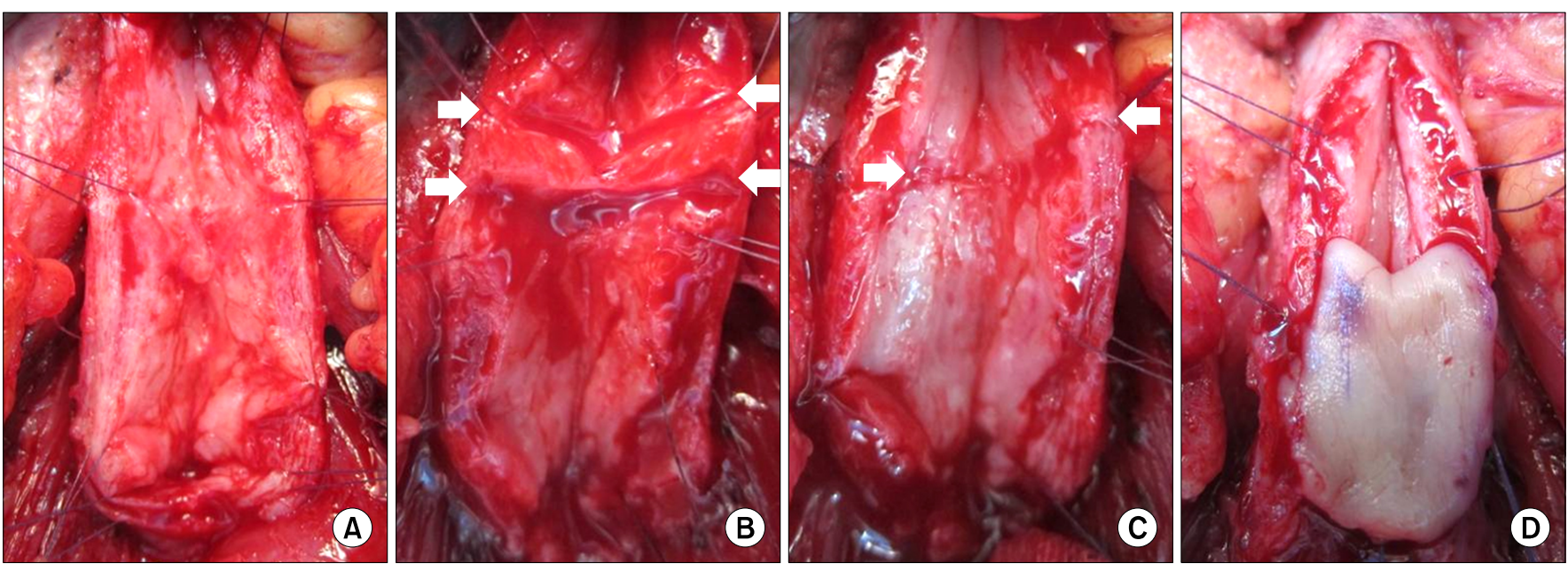

FiG. 4. Intraoperative picture of augmented nontransected anastomotic urethroplasty. (A) Bulbar urethra after ventral urethrotomy. Narrowest portion of the stricture is observed. (B) Incision through the mucosa and resection of the diseased mucosa (arrows) and scarred portion of the spongiosum. (C) Reanastomosis of the mucosa layer (arrows). (D) Ventral placement of the BMG to augment the urethral lumen.
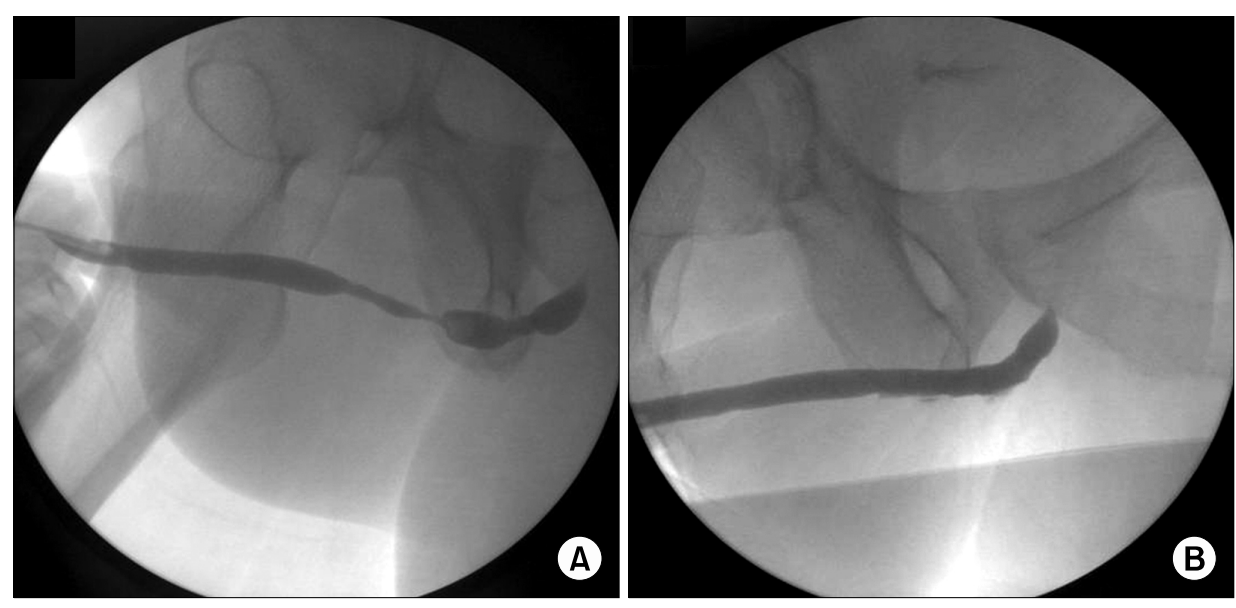

FiG. 5. Retrograde urethrographic appearance before (A) and after (B) surgery in the same patient (Fig. 4).

develop with the use of pedicled flaps rather than grafts [27]. A recent systematic review of graft augmentation urethroplasty techniques also showed that there is no significant difference between the average success rates of the dorsal and the ventral onlay when considering the bulbar urethra [28]. I agree with the opinion that in many cases the decision to perform augmented anastomotic urethroplasty is based on the surgeon's experience and the intraoperative determination of whether this approach would provide benefit in one of the ways described [27].

\section{1) Augmented nontransected anastomotic urethro- plasty}

Augmented nontransected anastomotic urethroplasty is a modification of augmented anastomotic urethroplasty and involves complete stricture excision without transection of the spongiosum [29]. A dorsal urethrotomy is performed until healthy mucosa is encountered and the decision is made to perform either a dorsal onlay substitution ure- throplasty or an augmented nontransected anastomotic urethroplasty with BMG. The BMG is placed dorsally and fixed to the cavernosal bodies [29]. An augmented nontransected anastomotic urethroplasty is preferred for cases in which there is an area of urethral obliteration that precludes the creation of a satisfactory lumen size with a simple substitution urethroplasty [29]. Forty-four men (23 substitution urethroplasty, 21 augmented nontransected anastomotic urethroplasty) with a median follow-up of 2.3 years were identified in one study. The overall success rate was $93 \%$ and was not statistically different between groups [29]. Augmented nontransected anastomotic urethroplasty can be performed with ventral urethrotomy and ventral placement of a BMG (Figs. 4, 5).

\section{MANAGEMENT OF PENILE URETHRAL STRICTURE}

Penile urethral strictures are different from bulbar ure- 

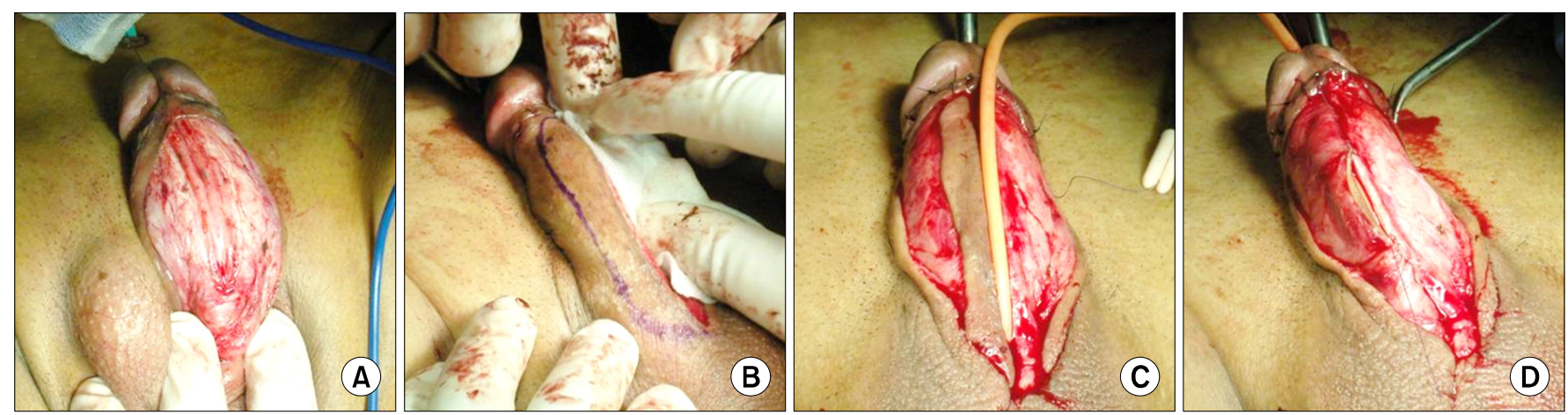

Fig. 6. Intraoperative picture of Orandi procedure. (A) Penile urethra after ventral urethrotomy. (B) An appropriate length and width of penile skin is designed. (C) Penile skin is mobilized on a dartos pedicle. (D) The free margin of the skin is sutured to the near margin of the urethra and the skin flap is flipped over and the dartos margin is then sutured to the other margin of the urethra.

thral strictures. In the penile urethra, excision and end-to-end anastomosis is not possible without causing penile chordee. In general, the choice of a surgical procedure for the management of penile urethral strictures is based on the etiology of the disease and the condition of the penis and urethra [30]. In patients with a normal penis, the penile skin, urethral plate, corpus spongiosum, and dartos fascia are available for urethral reconstruction, and a one-stage urethroplasty is the surgery of choice. By contrast, in patients with a failed hypospadias repair in whom the penile skin, urethral plate, and dartos fascia are not available for urethral reconstruction, a multistage urethroplasty is generally recommended [31].

\section{One-stage urethroplasty}

\section{1) Penile urethroplasty with flap}

In 1968, the American urologist Orandi [32] presented a new one-stage urethroplasty technique that applies the principles of pedicled skin grafting. Flaps are preferred to grafts in long, recurrent strictures [33]. The Orandi technique remains the gold standard for nonobliterative strictures within the penile shaft that are not due to lichen sclerosus. However, one has to be careful to get the width of the flap right, and this is not easy to judge, which is why the procedure carries a significant complication rate [2]. Over time, Quartey [34], McAninch [35], and Jordan and Stack [36] popularized a new one-stage flap urethroplasty based on Orandi's original techniques. Among these modified procedures derived from the Orandi technique, the penile circular fasciocutaneous flap, as first described by McAninch [35], is likely to be the most useful technique, with excellent cosmetic and functional results.

The benefits of using distal penile skin include its hairless nature, sufficient length (13 to $15 \mathrm{~cm}$ ), flexibility, and versatility [37]. Even in previously circumcised men, good cosmetic results can be attained with this technique. Earlier reports have proven this technique to be a reliable method of urethral reconstruction, particularly when the dorsal urethral plate can be preserved [38]. Whitson et al. [37] reported the long-term efficacy of distal penile circular fasciocutaneous flaps for single-stage urethroplasty in 124 patients with complex anterior urethral strictures. The median follow-up period was 7.3 years (range, 1 month to 19.5 years), and the median stricture length was $8.2 \mathrm{~cm}$ (range, 0.5 to $24 \mathrm{~cm}$ ). At 1, 3, 5, and 10 years, the overall estimated stricture-free survival rates were $95 \%, 89 \%$, $84 \%$, and $79 \%$, respectively [37].

During urethroplasty with a skin flap such as the Orandi technique, the flaps are traditionally placed on the ventral aspect of the stricture (Fig. 6), which can lead to sagging, sacculation, and diverticulum formation with resultant stasis and postvoid dribble. Bhandari et al. [39] used the pedicled penile/preputial skin flap as a dorsal onlay for managing complex recurrent anterior urethral strictures and compared it with traditional ventral onlay. Although the success rate was not statistically different between the two groups, pseudo-diverticulum or sacculation with postvoid dribble occurred in six patients in the ventral onlay group $(n=21)$ and none in the dorsal onlay group $(n=19)$ $(\mathrm{p}=0.01)[39]$.

\section{2) Penile urethroplasty with graft}

Since 1953, full-thickness free grafts have been used in the treatment of urethral stricture [40,41]. In 1994, Snodgrass [42] developed his own surgical technique, in which the urethral plate was incised for distal hypospadias repair, and later Hayes and Malone [43] recommended laying a BMG into the longitudinally incised urethral plate in patients with a failed hypospadias repair. In 2001, Asopa et al. [44] developed a similar technique mainly for the repair of penile urethral strictures and claimed that the procedure is easier to perform and better because the urethra is not mobilized. Pisapati et al. [45] have used Asopa's ventral sagittal urethrotomy and dorsal free graft technique for anterior urethral strictures in patients with penile (5) and bulbar (25) or penobulbar (15) urethral strictures. They reported an $87 \%$ overall success rate at a mean follow-up of 42 months [45].

Kulkarni et al. [25] described the use of a one-sided anterior urethroplasty utilizing the oral mucosa to preserve the 

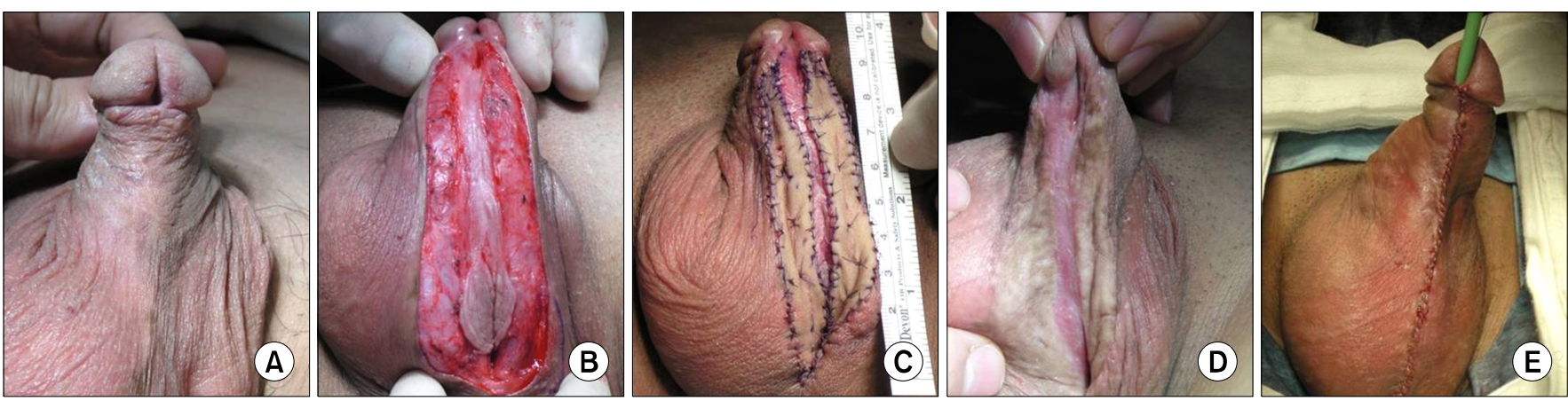

FiG. 7. Staged urethroplasty with full-thickness skin graft in a man with previous pediatric hypospadias repair. (A) Appearance of penile skin. Multiple scars are visible. (B) Urethral plate is preserved. (C) Full-thickness hairless groin skin is used. (D) After 4 months, inlay graft has excellent incorporation with urethral plate. (E) Stage 2 urethroplasty is completed.

lateral vascular supply to the urethra. Riechardt et al. [46] illustrated a modification of the original technique described by Barbagli et al. [17] that enables a better visualization of the mucosal margins while making the anastomosis, thus simplifying the original technique. The success rate of the modified technique was comparable with the original technique in a 3 -year experience with 18 patients [47].

The choice of surgical technique (flap vs. graft) can be made according to the status of the original urethral plate and penile corpus spongiosum tissue [48]. Basically, in patients with a wide, soft urethral plate and no fibrous spongiosum tissue, use of a graft is preferred. In contrast, in patients with a narrow, rigid urethral plate and fibrous spongiosum tissue, use of a flap is preferred [48]. Although a BMG seems to be better than a skin graft, the difference in success rate is so slight ( $82 \%$ vs. $78 \%$ ) that it does not justify the use of a BMG as a first choice [48].

\section{Two-stage urethroplasty}

Penile urethroplasty should be performed in a single stage whenever possible to avoid the patient discomfort and disability that can be caused by multistage procedures. However, in patients who have experienced failed hypospadias repair or in whom the penile skin, urethral plate, and dartos fascia are not suitable for urethral reconstruction, two-stage urethroplasty is recommended $[31,49]$. Historically, complex lengthy urethral strictures were treated by two-stage scrotal inlay urethroplasty [50-52]. Unfortunately, the results of scrotal inlay urethroplasties were less than optimal. Scrotal skin has poor waterproofing qualities with resultant urinary dermatitis and later cicatrization. The scrotal skin is also hair-bearing, and intraurethral hair growth can lead to infection and be a nidus for stone formation, further predisposing to recurrent stricture.

To circumvent these problems, Schreiter and Noll [53] have been proponents of staged meshed graft urethroplasty, generally using full-thickness preputial skin. Later, Carr et al. [54] reported their experience with mesh graft urethroplasty for complex urethral stricture disease using mainly split-thickness skin grafts from the thigh.
Twenty men underwent mesh graft urethroplasty for complex strictures, mostly after failed urethroplasty. Meshed split-thickness skin grafts from the thigh $(n=17)$ or full-thickness foreskin ( $n=3)$ was used [54]. Overall, the median time to closure was 5.5 months, and 6 men required revision before closure. A successful outcome was achieved in 12 of 15 men ( $80 \%$ ) with a median follow-up of 38 months. Five men did not undergo closure owing to patient refusal or because the graft was not ready to be closed. Although mesh graft urethroplasty is a valuable adjunct to the treatment of complex urethral strictures, it is a multistage rather than a two-stage procedure [54]. The authors believed that extrapenile split-thickness grafts are superior to extrapenile full-thickness grafts because they are more pliable and graft take is superior [54]. However, full-thickness hairless extragenital skin grafting has yielded an optimal success rate [55]. Considering shrinkage of the graft, I prefer using extragenital full-thickness skin grafts for two-stage urethroplasty (Fig. 7).

In 1995, Bracka [31] analyzed a personal series of over 600 cases of failed hypospadias repaired by the two-stage penile skin graft technique and concluded that a two-stage operation is an acceptable option that offers unique versatility, excellent reliability, and a sophistication of function and aesthetics that is hard to achieve with one-stage methods. In 2004, Snodgrass and Elmore [56] reported their initial experience with staged BMG (Bracha) urethroplasty after failed hypospadias surgery. Of the 25 cases, $3(12 \%)$ required a second grafting procedure before tubularization and four partial glans dehiscences occurred after tubularization, requiring reoperative glansplasty [56]. Barbagli et al. [49] reported the results of one-stage $(\mathrm{n}=29)$ and multistage $(\mathrm{n}=31)$ urethroplasty in adults following multiple failed hypospadias repairs. In that series, $39 \%$ of the patients required more than two planned surgeries owing to complications after the first stage, which required a new grafting procedure [57].

\section{MANAGEMENT OF PANURETHRAL STRICTURE}

Common causes of panurethral stricture involving the pen- 
ile and bulbar urethra are lichen sclerosus, urethral instrumentation, and catheterization [57,58]. Management of panurethral strictures remains a great challenge for urologists. When considering heroic efforts to reconstruct the urethra, it is important to appreciate that complex reconstruction carries a significant failure rate and that creation of a formal perineal urethrostomy is a reasonable option for patients who are not good candidates for surgical treatment, particularly in the elderly, who commonly sit down to void anyway [59]. Panurethral stricture may be treated by using one-stage or multistage techniques according to disease etiology and extent and on the basis of the surgeon's background and preference [59].

The most widely known approach is a "staged" SwinneyJohanson approach $[60,61]$, with marsupialization of the urethra to the surrounding skin, followed by tubularization of a strip 3 to 6 months later. Although the Johanson staged urethroplasty has long fallen out of favor as a first-line therapy, it is still a good surgical option for difficult and complicated urethral strictures, especially those in the pendulous part [62]. In strictures involving all parts of the urethra, total urethroplasty could be performed [62].

The penile circular fasciocutaneous flap, as first described by McAninch [35], can be another approach with advantages including hairless nature, sufficient length, and flexibility [37,38]. Morey et al. [63] developed a distal circumferential penile skin flap incorporating a ventral midline extension (Q-flap). The Q-flap provides an abundant hairless penile skin flap that enables one-stage panurethral reconstruction while eliminating the additional time and morbidity of harvesting further grafts [63]. El Dahshoury [64] used a zigzag-shaped annular penile fasciocutaneous flap (modified McAninch flap) to obtain a longer flap for reconstruction of pan-anterior urethral strictures. Berglund and Angermeier [65] suggested that the combination of a BMG and a genital skin flap (penile or scrotal) proved to be a reliable and durable method of one-stage repair for extensive and panurethral stricture disease. Erickson et al. [66] also showed that one-stage, segmental urethral replacement surgery is possible using the combination of a dorsal onlay BMG and a ventral onlay circular fasciocutaneous flap.

Tavakkoli Tabassi et al. [67] reported the surgical details and results of one-stage transperineal urethroplasty using dorsal BMG in the treatment of 17 men with panurethral stricture. The final success rate was $88.2 \%$ at a mean follow-up of 8.5 months [67]. Kulkarni et al. [25] developed a new one-sided anterior dorsal BMG urethroplasty while preserving the lateral vascular supply to the urethra. Kulkarni et al. [68] presented their experience with panurethral stricture repair using this one-stage, one-side dissection dorsal onlay repair with BMG. The records of 117 consecutive men who underwent treatment for panurethral stricture were reviewed. Mean stricture length was $14 \mathrm{~cm}$ and median follow-up was 59 months. The overall success rate was $83.7 \%$ with a success rate of $86.5 \%$ for primary urethroplasty and $61.5 \%$ in patients in whom ure- throplasty had previously failed. Most recurrent strictures developed at the proximal end of the graft [68].

\section{CONCLUSIONS}

The surgical treatment of urethral stricture is continually evolving. No one technique is appropriate for all situations and the successful surgeon will have a repertoire of methods from which to choose. Since the early 1990s, BMG was introduced in urethral reconstructive surgery and has become the first choice of most practicing urologists. The results of excision and end-to-end anastomosis for short sharp strictures of the bulbar urethra are excellent. Nonetheless, some surgeons are adopting a nontransecting approach. To transect or not to transect the bulbar urethra in nontraumatic urethral strictures remains an issue that is open to debate. When a patch is needed, either for augmentation or substitution urethroplasty for a bulbar urethral stricture, the evidence is in favor of using a graft. A $\mathrm{BMG}$ is easier to harvest, and the take is more reliable and has less donor site complications. There have been numerous debates about whether a graft should be placed dorsally or ventrally.

Penile urethral strictures are different from bulbar urethral strictures. Flaps are preferred to grafts in long, recurrent penile urethral strictures. The Orandi technique remains the gold standard for nonobliterative strictures within the penile shaft. Several surgeons have developed new one-stage flap urethroplasties based on the Orandi technique. Among these modified procedures, the penile circular fasciocutaneous flap, as first described by McAninch [35], seems to be the most useful technique with good surgical outcomes. Recently, one-stage dorsal BMG urethroplasty has become popular for the management of penile urethral stricture. However, in patients who have experienced failed hypospadias repair or in whom the penile skin and urethral plate are not suitable for urethroplasty, two-stage (usually multistage) urethroplasty is recommended [31,49].

Management of panurethral strictures remains a great challenge even for experienced urologists. We have to remember that perineal urethrostomy is a reasonable option for patients who are not good candidates for surgical treatments. Staged urethroplasty, such as the Johanson technique with or without the use of grafts, is still a good surgical option. As a one-stage operation, another approach uses a penile circular fasciocutaneous flap with several modifications or simultaneous use of BMG. Recently, one-stage dorsal BMG urethroplasty with perineal incision has been suggested as a useful technique.

\section{CONFLICTS OF INTEREST}

The authors have nothing to disclose.

\section{REFERENCES}

1. Chapple C, Barbagli G, Jordan G, Mundy AR, Rodrigues-Netto 
N, Pansadoro V, et al. Consensus statement on urethral trauma. BJU Int 2004;93:1195-202.

2. Andrich DE, Mundy AR. What is the best technique for urethroplasty? Eur Urol 2008;54:1031-41.

3. Bullock TL, Brandes SB. Adult anterior urethral strictures: a national practice patterns survey of board certified urologists in the United States. J Urol 2007;177:685-90.

4. Barbagli G, Palminteri E, Lazzeri M, Guazzoni G, Turini D. Long-term outcome of urethroplasty after failed urethrotomy versus primary repair. J Urol 2001;165(6 Pt 1):1918-9.

5. Wright JL, Wessells H, Nathens AB, Hollingworth W. What is the most cost-effective treatment for 1 to 2 -cm bulbar urethral strictures: societal approach using decision analysis. Urology 2006; 67:889-93.

6. Rourke KF, Jordan GH. Primary urethral reconstruction: the cost minimized approach to the bulbous urethral stricture. J Urol 2005;173:1206-10.

7. Barbagli G, Guazzoni G, Lazzeri M. One-stage bulbar urethroplasty: retrospective analysis of the results in 375 patients. Eur Urol 2008;53:828-33.

8. Santucci RA, Mario LA, McAninch JW. Anastomotic urethroplasty for bulbar urethral stricture: analysis of 168 patients. J Urol 2002;167:1715-9.

9. Eltahawy EA, Virasoro R, Schlossberg SM, McCammon KA, Jordan GH. Long-term followup for excision and primary anastomosis for anterior urethral strictures. J Urol 2007;177:1803-6.

10. Barbagli G, De Angelis M, Romano G, Lazzeri M. Long-term follow-up of bulbar end-to-end anastomosis: a retrospective analysis of 153 patients in a single center experience. J Urol 2007; 178:2470-3

11. Guralnick ML, Webster GD. The augmented anastomotic urethroplasty: indications and outcome in 29 patients. J Urol 2001;165:1496-501.

12. Singh O, Gupta SS, Arvind NK. Anterior urethral strictures: a brief review of the current surgical treatment. Urol Int 2011;86:1-10.

13. Morey AF, Kizer WS. Proximal bulbar urethroplasty via extended anastomotic approach--what are the limits? J Urol 2006; 175:2145-9.

14. Culty T, Boccon-Gibod L. Anastomotic urethroplasty for posttraumatic urethral stricture: previous urethral manipulation has a negative impact on the final outcome. J Urol 2007; 177:1374-7.

15. Andrich DE, Mundy AR. Non-transecting anastomotic bulbar urethroplasty: a preliminary report. BJU Int 2012;109:1090-4.

16. Barbagli G, Sansalone S, Romano G, Lazzeri M. Bulbar urethroplasty: transecting vs. nontransecting techniques. Curr Opin Urol 2012;22:474-7.

17. Barbagli G, Selli C, di Cello V, Mottola A. A one-stage dorsal free-graft urethroplasty for bulbar urethral strictures. Br J Urol 1996;78:929-32.

18. Andrich DE, Leach CJ, Mundy AR. The Barbagli procedure gives the best results for patch urethroplasty of the bulbar urethra. BJU Int 2001;88:385-9.

19. Bhargava S, Chapple CR. Buccal mucosal urethroplasty: is it the new gold standard? BJU Int 2004;93:1191-3.

20. Andrich DE, Mundy AR. What's new in urethroplasty? Curr Opin Urol 2011;21:455-60.

21. Barbagli G, Palminteri E, Guazzoni G, Montorsi F, Turini D, Lazzeri M. Bulbar urethroplasty using buccal mucosa grafts placed on the ventral, dorsal or lateral surface of the urethra: are results affected by the surgical technique? J Urol 2005;174:955-7.
22. Wang K, Miao X, Wang L, Li H. Dorsal onlay versus ventral onlay urethroplasty for anterior urethral stricture: a meta-analysis. Urol Int 2009;83:342-8.

23. Barbagli G, Sansalone S, Romano G, Lazzeri M. Ventral onlay oral mucosal graft bulbar urethroplasty. BJU Int 2011;108:1218-31.

24. Patterson JM, Chapple CR. Surgical techniques in substitution urethroplasty using buccal mucosa for the treatment of anterior urethral strictures. Eur Urol 2008;53:1162-71.

25. Kulkarni S, Barbagli G, Sansalone S, Lazzeri M. One-sided anterior urethroplasty: a new dorsal onlay graft technique. BJU Int 2009;104:1150-5

26. Abouassaly R, Angermeier KW. Augmented anastomotic urethroplasty. J Urol 2007;177:2211-5.

27. El-Kassaby AW, El-Zayat TM, Azazy S, Osman T. One-stage repair of long bulbar urethral strictures using augmented Russell dorsal strip anastomosis: outcome of 234 cases. Eur Urol 2008;53:420-4.

28. Mangera A, Patterson JM, Chapple CR. A systematic review of graft augmentation urethroplasty techniques for the treatment of anterior urethral strictures. Eur Urol 2011;59:797-814.

29. Welk BK, Kodama RT. The augmented nontransected anastomotic urethroplasty for the treatment of bulbar urethral strictures. Urology 2012;79:917-21.

30. Barbagli G, Lazzeri M. Urethral reconstruction. Curr Opin Urol 2006;16:391-5

31. Bracka A. Hypospadias repair: the two-stage alternative. Br J Urol 1995;76 Suppl 3:31-41.

32. Orandi A. One-stage urethroplasty. Br J Urol 1968;40:717-9.

33. Morey AF, Duckett CP, McAninch JW. Failed anterior urethroplasty: guidelines for reconstruction. J Urol 1997;158:1383-7.

34. Quartey JK. One-stage penile/preputial cutaneous island flap urethroplasty for urethral stricture: a preliminary report. J Urol 1983;129:284-7.

35. McAninch JW. Reconstruction of extensive urethral strictures: circular fasciocutaneous penile flap. J Urol 1993;149:488-91.

36. Jordan GH, Stack RS. General concepts concerning the use of genital skin islands for anterior urethral reconstruction. Atlas Urol Clin North Am 1997;5:23-44.

37. Whitson JM, McAninch JW, Elliott SP, Alsikafi NF. Long-term efficacy of distal penile circular fasciocutaneous flaps for single stage reconstruction of complex anterior urethral stricture disease. J Urol 2008;179:2259-64.

38. McAninch JW, Morey AF. Penile circular fasciocutaneous skin flap in 1-stage reconstruction of complex anterior urethral strictures. J Urol 1998;159:1209-13.

39. Bhandari M, Dubey D, Verma BS. Dorsal or ventral placement of the preputial/penile skin onlay flap for anterior urethral strictures: does it make a difference? BJU Int 2001;88:39-43.

40. Presman D, Greenfield DL. Reconstruction of the perineal urethra with a free full-thickness skin graft from the prepuce. J Urol 1953;69:677-80.

41. Devine PC, Horton CE, Devine CJ Sr, Devine CJ Jr, Crawford HH, Adamson JE. Use of full thickness skin grafts in repair of urethral strictures. J Urol 1963;90:67-71.

42. Snodgrass W. Tubularized, incised plate urethroplasty for distal hypospadias. J Urol 1994;151:464-5.

43. Hayes MC, Malone PS. The use of a dorsal buccal mucosal graft with urethral plate incision (Snodgrass) for hypospadias salvage. BJU Int 1999;83:508-9.

44. Asopa HS, Garg M, Singhal GG, Singh L, Asopa J, Nischal A. Dorsal free graft urethroplasty for urethral stricture by ventral sagittal urethrotomy approach. Urology 2001;58:657-9. 
45. Pisapati VL, Paturi S, Bethu S, Jada S, Chilumu R, Devraj R, et al. Dorsal buccal mucosal graft urethroplasty for anterior urethral stricture by Asopa technique. Eur Urol 2009;56:201-5.

46. Riechardt S, Pfalzgraf D, Dahlem R, Fisch M. Surgery illustrated--focus on details: dorsal buccal mucosal inlay for penile urethroplasty. BJU Int 2009;103:1444-7.

47. Pfalzgraf D, Kluth L, Isbarn H, Reiss P, Riechardt S, Fisch M, et al. The Barbagli technique: 3-year experience with a modified approach. BJU Int 2013;111(3 Pt B):E132-6.

48. Barbagli G, Morgia G, Lazzeri M. Retrospective outcome analysis of one-stage penile urethroplasty using a flap or graft in a homogeneous series of patients. BJU Int 2008;102:853-60.

49. Barbagli G, De Angelis M, Palminteri E, Lazzeri M. Failed hypospadias repair presenting in adults. Eur Urol 2006;49:887-94.

50. Turner-Warwick RT. A technique for posterior urethroplasty. J Urol 1960;83:416-9.

51. Leadbetter GW Jr. A simplified urethroplasty for strictures of the bulbous urethra. J Urol 1960;83:54-9.

52. Blandy JP, Singh M, Notley RG, Tresidder GC. The results and complications of scrotal-flap urethroplasty for stricture. Br J Urol 1971;43:52-7.

53. Schreiter F, Noll F. Mesh graft urethroplasty using split thickness skin graft or foreskin. J Urol 1989;142:1223-6.

54. Carr LK, MacDiarmid SA, Webster GD. Treatment of complex anterior urethral stricture disease with mesh graft urethroplasty. J Urol 1997;157:104-8.

55. Meeks JJ, Erickson BA, Gonzalez CM. Staged reconstruction of long segment urethral strictures in men with previous pediatric hypospadias repair. J Urol 2009;181:685-9.

56. Snodgrass W, Elmore J. Initial experience with staged buccal graft (Bracka) hypospadias reoperations. J Urol 2004;172(4 Pt 2):1720-4.

57. Barbagli G, Mirri F, Gallucci M, Sansalone S, Romano G, Lazzeri M. Histological evidence of urethral involvement in male patients with genital lichen sclerosus: a preliminary report. J Urol 2011;185:2171-6.

58. Lumen N, Hoebeke P, Willemsen P, De Troyer B, Pieters R, Oosterlinck W. Etiology of urethral stricture disease in the 21st century. J Urol 2009;182:983-7.

59. Peterson AC, Palminteri E, Lazzeri M, Guanzoni G, Barbagli G, Webster GD. Heroic measures may not always be justified in extensive urethral stricture due to lichen sclerosus (balanitis xerotica obliterans). Urology 2004;64:565-8.

60. Swinney J. Urethroplasty: an assessment after seven years' experience. Br J Urol 1957;29:293-7.

61. Johansen B. Reconstruction of the male urethra in strictures. Acta Chir Scand 1953;176(Suppl):1-103.

62. Al-Ali M, Al-Hajaj R. Johanson's staged urethroplasty revisited in the salvage treatment of 68 complex urethral stricture patients: presentation of total urethroplasty. Eur Urol 2001;39:268-71.

63. Morey AF, Tran LK, Zinman LM. Q-flap reconstruction of panurethral strictures. BJU Int 2000;86:1039-42.

64. El Dahshoury ZM. Modified annular penile skin flap for repair of pan-anterior urethral stricture. Int Urol Nephrol 2009;41:889-94.

65. Berglund RK, Angermeier KW. Combined buccal mucosa graft and genital skin flap for reconstruction of extensive anterior urethral strictures. Urology 2006;68:707-10.

66. Erickson BA, Breyer BN, McAninch JW. Single-stage segmental urethral replacement using combined ventral onlay fasciocutaneous flap with dorsal onlay buccal grafting for long segment strictures. BJU Int 2012;109:1392-6.

67. Tavakkoli Tabassi K, Mansourian E, Yarmohamadi A. One-stage transperineal repair of pan-urethral stricture with dorsally placed buccal mucosal grafts: results, complications, and surgical technique. Urol J 2011;8:307-12.

68. Kulkarni SB, Joshi PM, Venkatesan K. Management of panurethral stricture disease in India. J Urol 2012;188:824-30. 